\title{
Digestion of wood-based hemicellulose extracts as screened by in vitro gas production method and verified in vivo using sheep
}

\author{
Marketta Rinne ${ }^{a}$, Outi Kautto ${ }^{a}$, Kaisa Kuoppalaa , Seppo Ahvenjärvi ${ }^{a}$, Veikko Kitunen ${ }^{b}$, Hannu Ilvesniemi ${ }^{b}$, Stefan \\ Willförc $^{c}$, Riitta Sormunen-Cristian ${ }^{\text {a }}$ \\ ${ }^{a}$ Natural Resources Institute Finland (Luke), Green Technology, Fl-31600 Jokioinen, Finland \\ ${ }^{\mathrm{b}}$ Natural Resources Institute Finland (Luke), Bio-based Business and Industry, Fl-01370 Vantaa, Finland \\ cÅbo Akademi University, Johan Gadolin Process Chemistry Centre, FI-20500 Turku, Finland \\ e-mail: marketta.rinne@luke.fi
}

\begin{abstract}
The objective of the present study was to evaluate the potential of pressurized hot water extracted hemicellulose fractions from various wood species as feeds for ruminants. In Experiment 1, the fermentability of several hemicellulose extracts was screened using an in vitro gas production method. The samples were extracted from spruce (Picea abies) including mainly galactoglucomannan (GGM), from birch (Betula pendula) consisting mainly of xylan and from larch (Larix sibirica) consisting mainly of arabinogalactan. The GGM and xylan samples were readily fermented by rumen microbes while arabinogalactan was not. Based on the in vitro study, GGM was chosen for an in vivo digestibility trial using sheep, where it was fed at increasing proportions of diet dry matter $(0,47,94$ and 141 $\mathrm{g} \mathrm{kg}^{-1}$ ) in a Latin Square design. The in vivo organic matter digestibility of GGM was relatively low, 0.58 , but PHWE extracted hemicellulose has some potential as a feed for ruminants.
\end{abstract}

Key words: birch, digestibility, larch, pressurized hot water extraction, spruce

\section{Introduction}

Wood is the most abundant source of carbohydrates worldwide. The predominant components of wood are cellulose (400 to $450 \mathrm{~g} \mathrm{~kg}^{-1}$ dry matter [DM]), hemicelluloses (200 to $300 \mathrm{~g} \mathrm{~kg}^{-1} \mathrm{DM}$ ) and lignin (200 to $300 \mathrm{~g} \mathrm{~kg}^{-1} \mathrm{DM}$ ), which comprise more than $900 \mathrm{~g} \mathrm{~kg}^{-1} \mathrm{DM}$ of wood, the rest consisting of protein, minerals and other components (Sjöström 1993). Ruminants naturally utilize cellulose and hemicelluloses as major components of their diets, although they typically originate from grasses (Van Soest 1994). Wild ruminants including moose (Alces alces L.) also consume coniferous trees such as Pinus and Picea species, although their digestibility is low (Stolter et al. 2009). In a search for novel feed resources for ruminants, wood processing by-products provide an intriguing possibility.

The untreated wood is very poorly utilized by any animal including ruminants. The in vitro digestibility of DM of various tree species was poor with a range from 0.002 to 0.035 (Millett et al. 1970). Hardwood species (aspen, birch, maple) were more digestible than softwood species (pine and spruce), which exhibited hardly any digestibility. Because of the linkages of lignin to the carbohydrate fractions, some chemical or physical treatment or their combination is needed to improve their digestibility for ruminants (Millett et al. 1973). Pressurized hot water extraction (PHWE) is a novel method that can be used to extract hemicelluloses from wood (Leppänen et al. 2011). In this process, the temperature of pressurized water is kept between $100{ }^{\circ} \mathrm{C}$ and $375^{\circ} \mathrm{C}$. The best temperature of isolating polymeric hemicelluloses is $170^{\circ} \mathrm{C}-180^{\circ} \mathrm{C}$. At this temperature there will be no extensive degradation of polysaccharides and still the yield is high. Another approach is to recover dissolved hemicelluloses from the leachates of the mechanical pulping of softwoods (Xu et al. 2007).

Cellulose is a homopolymer of $\beta$-(1-4)-linked D-glucose units, while hemicelluloses are not a homogeneous compound but a group of mixed polysaccharides (Sjöström 1993). Spruce and pine (softwood) contain somewhat less hemicelluloses than birch (hardwood) and the composition of the hemicelluloses differ between these species (Saarinen et al. 1959). Glucomannans and galactoglucomannans are the predominant hemicelluloses of coniferous trees (spruce and pine) and xylans in deciduous trees (birch), while $\beta$-glucans are restricted to grasses. Norway spruce contained hemicelluloses ca. $250 \mathrm{~g} \mathrm{~kg}^{-1}$ and about $15 \mathrm{~g} \mathrm{~kg}^{-1}$ of these was galactoglucomannan (Willför and Holmbom 2004). Birch contained mainly xylans (226 g kg-1 DM), which was more than in the other hardwood species (aspen, oak, poplar, wattle and beech) investigated (Willför et al. 2005).

The in vitro gas production (GP) method is widely used in the assessment of ruminant feeds (Huhtanen et al. 2008). In brief, the sample is incubated in a buffer solution together with rumen fluid to provide the microbial inoculants. 
The gas produced by the microbes while degrading the sample is recorded and information of the sample digestion thus obtained. The advantages of in vitro methods compared to in vivo digestibility trials are shorter duration, lower cost, and smaller amount of feed needed.

The aim of this study was to screen the digestion of different types of hemicelluloses extracted using the novel PHWE method, which to our knowledge has not previously been evaluated as a method for feed production. The hemicellulose fractions studied were galactoglucomannan (GGM) extracted from spruce, xylan (XYL) extracted from birch, and arabinogalactan (AG) extracted from larch using a GP system (Exp. 1) and the hypothesis was that they would be readily fermented by rumen microbes in vitro. Based on Exp. 1., GGM showed the greatest potential as a feed ingredient and it was fed to sheep to determine the in vivo digestibility of it (Exp. 2) and to verify the results from the in vitro measurements.

\section{Materials and methods \\ In vitro gas production measurements of hemicellulose extracts (Exp. 1) \\ Extraction of hemicellulose for the in vitro gas production measurements}

The samples extracted from spruce (Picea abies) and containing mainly galactoglucomannan (GGM) originated from 3 different batches (GGM1, GGM2 and GGM3). A fraction consisting mainly of xylan (XYL) was extracted from birch (Betula pendula). Finally, larch (Larix sibirica) was used to produce mainly arabinogalactan (AG1 and AG2).

Hemicellulose GGM1 was recovered from a Finnish mill producing thermo-mechanical spruce pulp using different filtration techniques (Xu et al. 2007). The resulting concentrate was then spray-dried. Hemicelluloses GGM2, GGM3, $\mathrm{XYL}, \mathrm{AG} 1$ and $\mathrm{AG} 2$ for the in vitro gas production measurements were extracted by PHWE flow-through method in laboratory scale in $185^{\circ} \mathrm{C}$ (GGM, XYL) (Leppänen et al. 2011) in the laboratories of Luke (former Finnish Forest Research Institute Metla (Vantaa, Finland) or using batch-wise PHWE extraction (AG) (Song et al. 2008) at Åbo Akademi University (Turku, Finland). The extracts were dried with Rotavapor. In this equipment, constant-speed rotation under vacuum conditions and high temperature causes evaporation.

\section{Conduction of the in vitro gas production measurements}

The cumulative GP of the samples was estimated in the laboratory of Luke (former Agrifood Research Finland MTT), Jokioinen, Finland, using the equipment and method described by Huhtanen et al. (2008). In brief, $0.5 \mathrm{~g}$ of air dry sample was weighed into $120 \mathrm{ml}$ glass bottles with $67 \mathrm{ml}$ buffer solution and $13 \mathrm{ml}$ rumen fluid. In addition, there were three blank bottles in each incubation with only buffer and rumen fluid included to measure gas production in the absence of feed sample. Cumulative GP was recorded every $15 \mathrm{~min}$ for the 96-h incubation period.

Six separate incubations were conducted because all samples could not be included in each incubation due to extended period in production of various hemicellulose extracts. In addition to hemicellulose extracts, reference samples of grass silage, barley grain and potato starch were assessed in the same incubations to ensure that the level of sample fermentability remains at the same level between the incubations. Rumen fluid was collected from two ruminally fistulated Nordic Red cows fed a forage-based (600 g kg-1 DM) diet. The GP of GGM4 from Exp. 2 was conducted using a similar method with the exception that the equipment was supplied by ANKOM Technology (Macedon, NY, USA), where the bottle volume was $250 \mathrm{ml}$ and the amounts of buffer and rumen fluid were 60 and $20 \mathrm{ml}$, respectively.

\section{Calculation of the in vitro gas production results}

For each sample, a mean cumulative GP curve was calculated. The 2-pool Gompertz function (Schofield et al. 1994) was fitted to cumulative gas production profiles by the NLIN procedure (SAS Inst. Inc., Cary, NC, USA). The $\mathrm{V}_{\max }$ was calculated as the sum of volumes of the pools 1 and 2 from the 2-pool Gompertz model, and it represents the asymptote of the cumulative gas curve. A dynamic, mechanistic rumen model was used to predict the true in vivo digestibility of the potentially digestible DM (DIG) and the first-order rate of digestion ( $\left.k_{d}\right)$ as described by Huhtanen et al. (2008). The modelling was made using Powersim software (Powersim AS, Istalds $\varnothing$, Norway). 
The modelling of the digestibility was done using ruminal passage kinetic values representing either those of forage particles (retention time of $50 \mathrm{~h}$ divided in the proportions of 0.4:0.6 between non-escapable and escapable pools) or those of liquid (retention time of $13.33 \mathrm{~h}$ in the escapable pool). The digestibility of organic matter (OMD) was calculated using ash concentration of $11.7 \mathrm{~g} \mathrm{~kg}^{-1} \mathrm{DM}$ and indigestible OM concentration of $254 \mathrm{~g} \mathrm{~kg}^{-1}$ OM for all hemicellulose extracts based on measured values of GGM4 (proportion of lignin based, mainly phenolic compounds).

\section{In vivo digestibility trial using sheep (Exp. 2)}

\section{Extraction of hemicellulose for the digestibility measurement}

Based on results from Exp.1, GGM was chosen for an in vivo digestibility trial. An additional larger batch of GGM (GGM4) was prepared from saw meal from Norway spruce obtained from KotkaMill Ltd. (Kotka, Finland). It was extracted at Luke using PHWE flow-through equipment of 300-I capacity (Leppänen et al. 2011) by placing freezedried saw dust $(90 \mathrm{~kg})$ into the extraction chamber. The temperature of water was $185^{\circ} \mathrm{C}$, water flow-through rate was $201 \mathrm{~min}^{-1}$, extract collection time was $45 \mathrm{~min}$ and pressure 20 bar. After extraction, the raw material was concentrated with $5 \mathrm{kDa}$ membrane filter with an average flow rate of $25 \mathrm{~kg} \mathrm{~h}^{-1}$ in $30-45^{\circ} \mathrm{C}$ temperature. The concentrate was evaporated in low pressure and dried at $60^{\circ} \mathrm{C}$.

\section{Conduction of the digestibility trial}

The in vivo digestibility was determined in sheep using the total faecal collection method. The basal feed was grass silage of early cut mixture of timothy (Phleum pratense) and meadow fescue (Festuca pratensis). Silage was prepared on 17 June 2009, slightly prewilted, precision-chopped and ensiled into a bunker silo using a formic acid based additive. Four mature rams (Finnsheep $\times$ Texel crossbred, live weight $91 \pm 5.0 \mathrm{~kg}$ ) were used to estimate GGM4 in vivo digestibility in a $4 \times 4$ Latin square experiment with four experimental periods each lasting for 21 days, the last 7 days being used for faecal and urinary collection. Data from the last 7 days were used for calculation of results. The sheep had free access to water and received $15 \mathrm{~g}$ per day of a commercial mineral mixture (Lammas Hertta Muro, Suomen Rehu Ltd., Hyvinkää, Finland) and $10 \mathrm{~g}$ per day of $\mathrm{NaCl}$. The apparent total digestibility of nutrients was calculated as daily averages (g) of: (intake - faecal output) / faecal output. The metabolic faecal organic matter in relation to DM intake (MFOM) was calculated as (faecal organic matter - faecal NDF) $\mathrm{kg}^{-1}$ DM intake.

Before feeding, GGM4 was ground using a $6 \mathrm{~mm}$ sieve and mixed with grass silage. Total DM intake was restricted to $41 \mathrm{~g} \mathrm{~kg}^{-1}$ live weight ${ }^{0.75}$ and GGM4 replaced 0, 47, 94 and $141 \mathrm{~g} \mathrm{~kg}^{-1} \mathrm{DM}$ in the total diet. The levels were chosen to provide linear increments of GGM4 and a relatively low maximum level was chosen partly because we had no previous experience of the palatability and suitability of GGM4 as a feed and partly because of practical reasons (availability of GGM4). For the accuracy of the determination of digestibility by the regression method, higher amounts of the experimental feed would have been useful.

\section{Chemical analyses}

The DM content of GGM4 was determined by oven drying at $105^{\circ} \mathrm{C}$ for 20 hours and ash content after ignition in a muffle furnace at $600^{\circ} \mathrm{C}$ for $2 \mathrm{~h}$ (AOAC 1990; method 942.05). The carbon and nitrogen (N) contents of GGM4 were analysed by Leco (CHN analyser, ISO 10694 [C], ISO 13878 [N] methods) and the sugar content by acid methanolysis (Willför et al. 2009). The major and trace elements of GGM4 were measured on the basis of the wet ashed samples using ICP emission spectrometer ICP (IRIS), wet digestion $\left(\mathrm{HNO}_{3}-\mathrm{H}_{2} \mathrm{O}_{2}\right)$.

Silage DM concentration was determined similarly as that of GGM4, but it was corrected for the loss of volatile substances (lactic acid, volatile fatty acids and ammonia) according to Huida et al. (1986). Silage and faeces $N$ content was analyzed using the Dumas method with Leco FP428- analyzer (Leco Corp., St Joseph, USA) (OAOC 1990 method 96.06). Neutral detergent fibre (NDFom) was analysed according to Van Soest et al. (1991) without heat-stable amylase and expressed exclusive of residual ash. Water-soluble carbohydrates in silage were analyzed according to Somogyi (1945). Silage in vitro organic matter digestibility (OMD) was analyzed using pepsin-cellulase solubility as described by Huhtanen et al. (2006). The fermentation quality of the silage samples was also analyzed: pH, volatile fatty acids (Huhtanen et al. 1998), lactic acid (Haacker et al. 1983), and ammonia N (McCullough 1967). Gross energy value of freeze dried urine samples was determined with Parr 6200 Oxygen Bomb Calorimeter (Parr Instrument Co. Moline, IL 61265, USA) using benzoic acid (CAS 65-85-0, Cat No 3415, Parr Instrument Company) as a standard. 


\section{Statistical analyses}

In Exp. 1, several in vitro GP incubations were conducted for each feed, but as they were not true replicates, the results have not been statistically tested. The results from the in vivo digestibility trial (Exp. 2) were analyzed using the GLM procedure of SAS (SAS Inst. Inc., Cary, NC, USA), and the treatment effects were evaluated using polynomial contrasts. As only linear effects were significant, only they are presented in the Table 1.

\section{Results \\ In vitro gas production measurements (Exp. 1)}

Almost all GGM and most XYL incubations resulted in typical cumulative gas production curves, while for AG, only less than one third of the incubations resulted in typical gas curves (Table 1, Fig. 1). For AG, extremely long times before significant gas production occurred were typical (Fig. 1). Based on 19 unsuccessful incubations out of 28 in total, rumen microbes did not seem to be able to fully utilize AG. However, GGM and XYL produced consistently similar GP curves.

Table 1. In vitro gas production results of wood based hemicellulose extracts and reference samples measured using ruminal digesta passage kinetic parameters for forage and liquid

\begin{tabular}{|c|c|c|c|c|c|c|c|c|c|c|}
\hline & \multicolumn{7}{|c|}{ Hemicellulose extracts ${ }^{a}$} & \multicolumn{3}{|c|}{ Reference samples } \\
\hline & GGM1 & GGM2 & GGM3 & GGM4 & $X Y L$ & AG1 & AG2 & Silage & Barley & Starch \\
\hline \multicolumn{11}{|c|}{ Number of incubations } \\
\hline Total & 14 & 13 & 12 & 5 & 13 & 15 & 13 & 9 & 11 & 12 \\
\hline Converged & 14 & 12 & 12 & 5 & 11 & 3 & 6 & 9 & 11 & 12 \\
\hline \multicolumn{11}{|c|}{ Calculated using ruminal passage kinetics for forages } \\
\hline$V_{\text {max }}^{b}$ & 262.0 & 333 & 293 & 260 & 340 & 240 & 201 & 222 & 310 & 369 \\
\hline $\mathrm{SE}^{\mathrm{C}}$ & 10.0 & 10.8 & 10.8 & 16.7 & 11.3 & 18.7 & 15.3 & 12.5 & 11.3 & 10.8 \\
\hline $\mathrm{DIG}^{\mathrm{d}}$ & 0.951 & 0.947 & 0.937 & 0.944 & 0.954 & 0.905 & 0.527 & 0.863 & 0.919 & 0.965 \\
\hline SE & 0.0189 & 0.0204 & 0.0204 & 0.0316 & 0.0213 & 0.0409 & 0.0289 & 0.0236 & 0.0213 & 0.0204 \\
\hline$k_{d}^{e}$ & 0.151 & 0.139 & 0.123 & 0.120 & 0.153 & 0.295 & 0.030 & 0.071 & 0.105 & 0.196 \\
\hline SE & 0.0169 & 0.0183 & 0.0183 & 0.0212 & 0.0191 & 0.0366 & 0.0259 & 0.0211 & 0.0191 & 0.0183 \\
\hline OMD $^{f}$ & 0.705 & 0.702 & 0.694 & 0.694 & 0.707 & 0.671 & 0.391 & 0.728 & 0.858 & 0.962 \\
\hline SE & 0.0141 & 0.0152 & 0.0152 & 0.0236 & 0.0159 & 0.0304 & 0.0215 & 0.0176 & 0.0159 & 0.0152 \\
\hline
\end{tabular}

Calculated using ruminal passage kinetics for liquid

\begin{tabular}{rccccccc} 
DIG & 0.814 & 0.805 & 0.778 & 0.788 & 0.829 & 0.750 & 0.356 \\
SE & 0.0236 & 0.0255 & 0.0255 & 0.0395 & 0.0266 & 0.0509 & 0.0360 \\
$k_{d}$ & 0.100 & 0.095 & 0.085 & 0.088 & 0.107 & 0.147 & 0.022 \\
SE & 0.0061 & 0.0066 & 0.0066 & 0.0102 & 0.0069 & 0.0132 & 0.0093 \\
OMD & 0.604 & 0.597 & 0.576 & 0.584 & 0.615 & 0.556 & 0.264 \\
SE & 0.0175 & 0.0189 & 0.0189 & 0.0292 & 0.0197 & 0.0378 & 0.0267 \\
\hline
\end{tabular}

${ }^{\mathrm{a}} \mathrm{AG}=$ arabinogalactan from larch, GGM = galactoglucomannan from spruce, $\mathrm{XYL}=$ xylan from birch; ${ }^{\mathrm{b}} \mathrm{V}_{\max }=\mathrm{maximal} \mathrm{volume}$ of gas ( $\mathrm{ml} \mathrm{g}^{-1}$ $\mathrm{DM}) ;{ }^{\mathrm{c}} \mathrm{SE}=$ standard error; ${ }^{\mathrm{d}} \mathrm{DIG}=$ simulated in vivo digestibility of potentially digestible dry matter (DM) measured with gas production $\left(\mathrm{g} \mathrm{g}^{-1} \mathrm{DM}\right) ;{ }^{\mathrm{e}} \mathrm{k}_{\mathrm{d}}=$ rate of digestion $\left(1 \mathrm{~h}^{-1}\right) ;{ }^{f} \mathrm{OMD}=$ digestibility of organic matter, $\mathrm{g} \mathrm{g}^{-1} \mathrm{OM}$

The $V_{\text {max }}$ values of the GGM and XYL extracts were within the same range as those from the reference samples. The ruminal passage kinetic parameters used had a remarkable effect on the modelled digestibility results of the samples. The DIG values using passage kinetic parameters for forages of the GGM and XYL were even higher than those of barley grain, which represents a typical energy rich supplement of ruminants. When the passage kinetic parameters for liquid were used, the DIG values decreased on average by $149 \mathrm{~g} \mathrm{~kg}^{-1}$ and were clearly lower than those of the lowest digestibility reference sample, grass silage. 


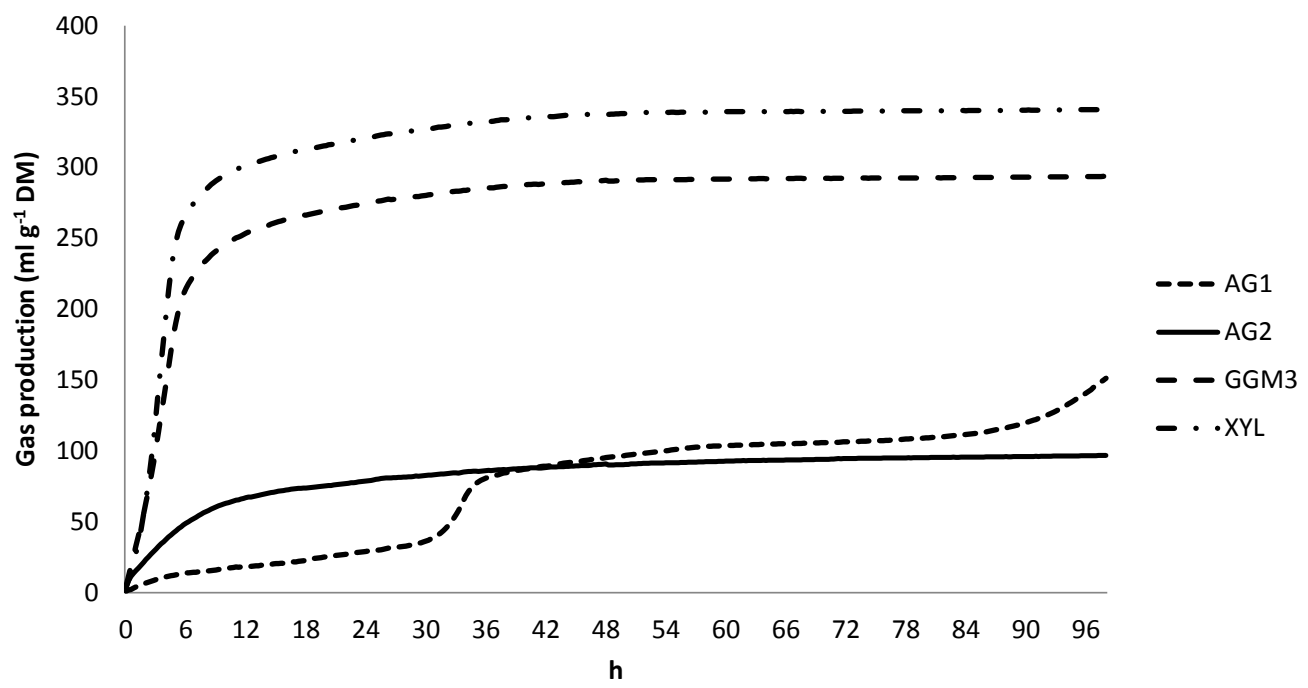

Fig. 1. Typical cumulative in vitro gas production curves in Exp. 1 for galactoglucomannan (GGM3), xylan (XYL) and arabinogalactan (AG1 and AG2)

\section{In vivo digestibility trial (Exp. 2)}

The basal silage had a DM concentration of $226 \mathrm{~g} \mathrm{~kg}^{-1}, \mathrm{pH}$ of 3.96 and D-value of $679 \mathrm{~g} \mathrm{~kg}^{-1} \mathrm{DM}$. On DM basis it contained $71 \mathrm{~g} \mathrm{~kg}^{-1}$ ash, $23.8 \mathrm{~g} \mathrm{~kg}^{-1} \mathrm{~N}, 538 \mathrm{~g} \mathrm{~kg}^{-1}$ NDFom, $70.5 \mathrm{~g} \mathrm{~kg}^{-1}$ lactic acid, $21.9 \mathrm{~g} \mathrm{~kg}^{-1}$ acetic acid and $0.2 \mathrm{~g} \mathrm{~kg}^{-1}$ butyric acid, and the proportion of ammonia $\mathrm{N}$ in total $\mathrm{N}$ was $66 \mathrm{~g} \mathrm{~kg}^{-1}$. The silage was of good quality based on nutritional and preservation characteristics.

The chemical composition of GGM4 is presented in Table 2. On OM basis ( $\mathrm{g} \mathrm{g}^{-1}$ ), GGM4 contained 0.747 hemicelluloses and uronic acids, and 0.254 lignin based, mainly phenolic compounds. The NDFom method proved to be an unsuitable method for the hemicellulose extract as although it by definition should be pure NDFom, it was fully solubilised in the neutral detergent solution and no result could be obtained. Thus a value of zero was used for the NDFom concentration of GGM4 in the calculation of NDFom digestibility in Exp. 2.

Table 2. The composition of the hemicellulose extract (GGM4) used in the in vivo digestibility trial

\begin{tabular}{|c|c|c|c|}
\hline Chemical composition & (g kg ${ }^{-1}$ dry matter) & Other elements & (mg kg ${ }^{-1}$ dry matter) \\
\hline Ash & 11.7 & Calcium & 2740 \\
\hline Carbon & 480 & Phosphorus & 88.4 \\
\hline \multirow[t]{2}{*}{ Nitrogen } & 0.8 & Potassium & 569 \\
\hline & & Magnesium & 267 \\
\hline Sugar composition & ( $\mathrm{g} \mathrm{kg}^{-1}$ organic matter) & Sodium & 625 \\
\hline Mannose & 465 & Iron & 252 \\
\hline Glucose & 106 & Copper & 96.8 \\
\hline Galactose & 61.7 & Sulphur & 889 \\
\hline Xylose & 80.5 & Aluminium & $<17.1$ \\
\hline Arabinose & 12.2 & Boron & 9.87 \\
\hline Rhamnose & 5.0 & Cadmium & $<0.107$ \\
\hline Glucuronic acid & 0.3 & Chromium & 0.78 \\
\hline Galacturonic acid & 16.2 & Manganese & 127 \\
\hline \multirow[t]{3}{*}{ 4-O-methyl glucuronic acid } & Not detected & Nickel & 2.21 \\
\hline & & Lead & 2.42 \\
\hline & & Zinc & 30.3 \\
\hline
\end{tabular}




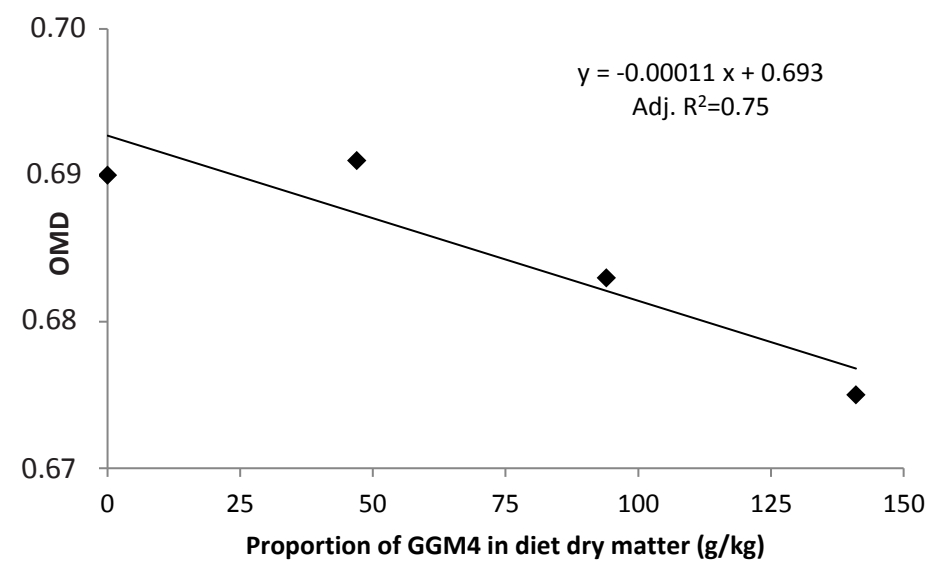

Fig. 2. In vivo organic matter digestibility (OMD) in sheep of diets based on grass silage and galactoglucomannan (GGM4) in varying proportions in Exp. 2.

In vivo digestibility

Intake and digestibility values of diets containing different levels of GGM4 are presented in Table 3. There were no differences in the DM and NDFom intake between the diets, but the OM intake tended to increase when the proportion of GGM4 increased due to the low ash concentration of GGM4. One sheep exhibited some intake problems, which were unrelated to the experimental treatments. The level of GGM4 in the diet did not affect DM digestibility, but the digestibility of diet OM tended to decrease $(p=0.076)$ and that of NFDom decreased $(p<0.001)$ as the proportion of GGM4 increased (Table 1, Fig. 2 ) and that of neutral detergent solubles increased $(p<0.001)$. The urinary gross energy output decreased $(p=0.040)$ with increasing amount of GGM4 in the diet. The linear regression equation of the diet OM digestibility $\left(\mathrm{g} \mathrm{kg}^{-1}\right)$ was: $-0.0011( \pm 0.00035) \times$ concentration of GGM in the diet $\left(\mathrm{g} \mathrm{kg}^{-1} \mathrm{DM}\right)+0.693( \pm 0.0031)\left(n=4, \mathrm{Adj} . \mathrm{R}^{2}=0.75\right)$. Based on the regression equation, the OMD of GGM4 was 0.58 .

Table 3. Intake and digestibility of hemicellulose extract GGM4 in the digestibility trial using sheep

\begin{tabular}{|c|c|c|c|c|c|c|}
\hline & \multicolumn{4}{|c|}{ Level of GGM4 } & \multirow{2}{*}{$\mathrm{SEM}^{\mathrm{a}}$} & \multirow{2}{*}{$p$-value ${ }^{\mathrm{b}}$} \\
\hline & 1 & 2 & 3 & 4 & & \\
\hline $\begin{array}{l}\text { Proportion of GGM4 in diet dry matter } \\
\left(\mathrm{DM} ; \mathrm{g} \mathrm{kg}^{-1}\right)\end{array}$ & 0 & 47 & 94 & 141 & & \\
\hline \multicolumn{7}{|l|}{ Intake (g day ${ }^{-1}$ ) } \\
\hline DM & 1231 & 1258 & 1243 & 1273 & 15.7 & \\
\hline Organic matter & 1142 & 1170 & 1160 & 1192 & 14.6 & \\
\hline Neutral detergent fibre & 663 & 645 & 606 & 590 & 8.4 & \\
\hline \multicolumn{7}{|l|}{ Digestibility } \\
\hline DM & 0.670 & 0.672 & 0.665 & 0.658 & 0.0052 & 0.11 \\
\hline Organic matter & 0.690 & 0.691 & 0.683 & 0.675 & 0.0054 & 0.07 \\
\hline Neutral detergent fibre & 0.668 & 0.659 & 0.636 & 0.602 & 0.0081 & $<0.001$ \\
\hline Neutral detergent solubles ${ }^{c}$ & 0.719 & 0.731 & 0.734 & 0.746 & 0.0044 & 0.006 \\
\hline Metabolic faecal OM output ${ }^{d}$ & 109 & 118 & 131 & 140 & 2.7 & $<0.001$ \\
\hline Faecal $\mathrm{N}$ output, $\mathrm{g} \mathrm{d}^{-1}$ & 5.32 & 9.58 & 9.90 & 10.17 & 0.256 & 0.047 \\
\hline Urinary gross energy output, $\mathrm{MJ} \mathrm{d}^{-1}$ & 1.41 & 1.23 & 1.31 & 1.29 & 0.030 & 0.040 \\
\hline
\end{tabular}

${ }^{\mathrm{a}}=$ standard error of the mean; ${ }^{\mathrm{b}}=$ linear polynomial contrast of the level of $\mathrm{GGM} 4 ;{ }^{\mathrm{c}}=$ neutral detergent soluble $=\mathrm{OM}-\mathrm{NDF}$;

${ }^{\mathrm{d}}$ = faecal OM - faecal NDF, $\mathrm{g} \mathrm{kg}^{-1} \mathrm{DM}$ intake 


\section{Discussion \\ In vitro gas production (Exp. 1)}

The results of the GP showed that GGM and XYL were readily fermented by the rumen microbes while AG was not. In several AG incubations, the gas production remained extended periods at a very low level (in four cases for approximately $30 \mathrm{~h}$, and in 11 cases for $90 \mathrm{~h}$ ), which indicates that some kind of adaptation of the microbes might eventually have happened, but the total gas production was still low compared to other hemicellulose extracts. In some cases there seemed to be a small readily fermentable pool of substrates (Fig. 1). The structure of AG is remarkably branched and almost every unit of the backbone of AG carries a branch. As a result the degree of polymerization of the AG is two times higher than that of GGM. This kind of structure causes low viscosity and high solubility in water. The backbone of GGM is in turn a linear or slightly branched (Sjöström 1993). The difference in the structure between the different hemicelluloses might explain the variation in GP as branched molecules are degraded more slowly and/or incompletely (Van Soest 1994).

The applicability of the in vitro gas production technique is greatly dependent on the methods used for the calculation of results (Huhtanen et al. 2008). Currently, there is no information about the ruminal passage kinetics of the extracted hemicelluloses. They are, however, water-soluble so that it is likely that their passage through rumen resembles more that of liquid than that of forage particles. In the current data, the estimated OMD of GGM4 using the passage kinetics for forages resulted in a value 0.700 which is clearly higher than the value determined in vivo (0.58). However, when the OMD was calculated using a faster rumen passage rate representing the liquid outflow, which can be justified by the water solubility of hemicellulose extracts, the in vitro OMD was almost identical (0.584) with the in vivo value.

\section{In vivo digestibility (Exp. 2)}

The unprocessed wood materials are practically indigestible for ruminants (Millet et al. 1970), but using various chemical or physical treatments, their digestibility can be markedly increased. Saarinen et al. (1959) determined the in vivo digestibility of 40 wood pulps produced by various pulping methods and reported a range in digestibility from 0.27 to 0.90 depending on the lignin content. The in vivo digestibility of bleached (lignin erased and the pulp whitened) chemical pulp fines from mixed hardwood was 0.78 for DM and 0.86 for carbohydrates (Millett et al. 1973) indicating that the material had a high energy value for ruminants. Näsi (1984) evaluated the in vivo sheep digestibility of dissolved pulp and pulp hydrolysed with acetic acid from birch. The OMD of dissolved pulp was as high as 0.75 while that of hydrolysed pulp only 0.40 .

The OMD value determined in the current study (0.58) was within the range of studies mentioned in the previous chapter, but relatively low compared to the typical energy supplements used for ruminants. If the oligomers and polymers derived from hemicellulose pass through the rumen unfermented in the liquid phase and are poorly degraded in the lower tract, this would lead to low digestibility. Further, the processing factors such as high amount of lignin residues ( 0.254 of $\mathrm{OM}$ ) and possible physicochemical changes during drying may have contributed to the relatively low digestibility of GGM4.

Although the $k_{d}$ of hemicellulose fractions was relatively high (between the values of barley and starch in the current data set, and clearly higher than for grass silage), fast passage from rumen would inevitably mean that a large proportion of them would flow to the lower tract before they are fermented in the rumen. Typically in PHWE extracts, ca. 0.1 of the sugars are as monomers and the rest as polymers or oligomers (Leppänen et al. 2011). The GGM4 was filtrated so that it did not contain any monomers. It is likely that the PHWE extracted compounds originating from hemicellulose would be digestible in the lower tract either by the mammalian enzymes or by microbial fermentation in the hind gut at least to some extent.

The increasing amount of MFOM hints for increased passage of non-NDF components into the lower tract. Increasing faecal $\mathrm{N}$ output with increasing proportion of GGM4 indicates that there was increased microbial digestion in the lower tract. When lignin concentration is $250 \mathrm{~g} \mathrm{~kg}^{-1} \mathrm{DM}$ and faecal metabolic OM is approximately $100 \mathrm{~g} \mathrm{~kg}^{-1} \mathrm{DMI}$, potential in vivo OMD would be 0.65 . This value means that most potentially digestible material was digested and that lignin did not prevent digestion of the carbohydrates similarly as in intact (not extracted) cell wall material. Also the increased digestibility of cell solubles with increasing GGM4 concentration in the diet indicates that the digestion of the hemicellulose extract was high. Further, gross energy output in urine decreased with increasing GGM proportion in the diet, which indicates that the phenolic compounds in GGM were not excreted in urine. It seems likely that the low digestibility of GGM4 can mainly be attributed to the high concentration of phenolic residues in the extract. Possibly they may have adverse effects on the microbial fibre digestion in the rumen. 
Wood derived products have been used as feed supplements for lambs (Zelenak et al. 1979, Hatfield et al. 1998), growing cattle (Crawford et al. 1978, Zinn 1993) and lactating dairy cows (Murphy et al. 1993, Herrick et al. 2012). The amount used on diet DM basis for growing cattle and dairy cows has been up to 10\% (Crawford et al. 1978, Murphy et al. 1993). The performance of the animals receiving wood-derived feed products has typically been similar or slightly poorer than that of the control animals. These studies show that various types of wood molasses have successfully been used without deleterious effects on animal health and productivity or animal products, which indicates that there are no biological obstacles for incorporating them into ruminant diets (Näsi 1984). Further, consumption of up to $15 \%$ of GGM4 in the current experiment did not affect the feed intake of the rams, and no veterinary treatments were required during the experiment.

The main factors determining the usefulness of wood by-products as feeds are the cost relative to alternative feeds and the availability of suitable products. With an increasingly sophisticated bioeconomy, ruminants may play a role in utilizing wood-products such as hemicelluloses, which have little value for other uses e.g. in paper production or as an energy source. The hemicellulose extracts contain very little $\mathrm{N}$ and $\mathrm{P}$, which may be a further advantage in the form of increased nutrient use efficiency, if the basal diet is high in those nutrients. The feasibility of using wood derived carbohydrates as energy sources for ruminants depends on the cost of the raw material and the processing, preservation and logistics as well as supply chain acceptance, while there are no regulatory or biological obstacles in using them.

\section{Conclusions}

The in vitro gas production technique proved useful in screening the ability of rumen microbes to ferment various hemicellulose extracts produced using the pressurized hot water extraction method. Galactoglucomannan from spruce and xylose from birch were highly fermentable while arabinogalactan from larch was not. The in vivo OM digestibility of galactoglucomannan was however relatively low, 0.58 , which may at least partly be explained by a fast passage through rumen of water-soluble substrates and the high content of phenolic residues in the extract. Feeding up to $150 \mathrm{~g} \mathrm{~kg}^{-1}$ diet DM of galactoglucomannan to sheep was successful and the energy value of the hemicellulose extract was reasonable, which indicates that hemicellulose extracts from PHWE process have some potential as a feed for ruminants.

\section{Acknowledgements}

The research leading to these results has received funding from the European Union's Seventh Framework Programme for research, technological development and demonstration under grant agreement no FP7-266367 as part of the project SOLID (Sustainable Organic and Low Input Dairying). The funding of Raisio Ltd. Scientific foundation for Outi Kautto is greatfully acknowledged.

\section{References}

AOAC 1990. Official Methods of Analysis. Association of Official Analytical Chemists, Inc., Arlington, VA. 1298 p.

Crawford, D.F., Anthony, W.B. \& Harris, R.R. 1978. Evaluation of concentrated hemicellulose extract as cattle feed. Journal of Animal Science 46: 32-40.

Haacker, K., Block, H.J. \& Weissbach, F. 1983. Zur kolorimetrischen Milchsäurebestimmung in Silagen mit p-Hydroxydiphenyl. (On the colorimetric determination of lactic acid in silages with p-hydroxydiphenyl). Archiv für Tierernährung 33: 505-512.

Hatfield, P.G., Hopkins, J.A., Shawn Ramsay, W. \& Gilmore, A. 1998. Effects of level of protein and type of molasses on digesta kinetics and blood metabolites in sheep. Small Ruminant Research 28: 161-170.

Herrick, K.J., Hippen, A.R., Kalscheur, K.F., Anderson, J.L., Ranatunga, S.D, Patton, R.S. \& Abdullah, M. 2012. Lactation performance and digestibility of forages and diets in dairy cows fed a hemicellulose extract. Journal of Dairy Science 95: 3342-3353.

Huhtanen, P.J., Blauwiekel, R. \& Saastamoinen, I. 1998. Effects of intraruminal infusions of propionate and butyrate with two different protein supplements on milk production and blood metabolites in dairy cows receiving grass silage based diet. Journal of the Science of Food and Agriculture 77: 213-222.

Huhtanen, P., Nousiainen, J. \& Rinne, M. 2006. Recent developments in forage evaluation with special reference to practical applications. Agricultural and Food Science 15: 293-323.

Huhtanen, P., Seppälä, A., Ots, M., Ahveniärvi, S. \& Rinne M. 2008. In vitro gas production profiles to estimate extent and effective first-order rate of neutral detergent fibre digestion in the rumen. Journal of Animal Science 86: 651-659.

Huida, L., Väätäinen, H. \& Lampila, M. 1986. Comparison of dry matter contents in grass silages as determined by oven drying and gas chromatographic water analysis. Annales Agriculturae Fenniae 25: 215-230.

Leppänen, K., Spetz, P., Kitunen, V. \& Ilvesniemi, H. 2011. Pressurized hot water extraction of hemicellulose using a flow-through system. Wood Science and Technology 45: 223-236. 
McCullough, M.E. 1967. The determination of ammonia in whole blood by direct colorimetric method. Clinica Chimica Acta 17: 297-304.

Millett, M.A., Baker, A.J., Fenst, W.C., Mellenberger R.W. \& Slatter, L.D. 1970. Modifying wood to increase it's in vitro digestibility. Journal of Animal Science 31: 781-788.

Millett, M.A., Baker, A.J., Feist, W.C., Mellenberger, R.W. \& Satter, L.D. 1973. Pulp and papermaking residues as feedstuffs for ruminants. Journal of Animal Science 37: 599-607.

Murphy, M,. Khalili, H. \& Huhtanen, P. 1993. The substitution of barley by other carbohydrates in grass silage based diets to dairy cows. Animal Feed Science and Technology 41: 279-296.

Näsi, M. 1984. Evaluation of various types of forest biomass and wood processing residues as feed for ruminants. Journal of Agricultural Science in Finland 56: 205-212.

Saarinen, P., Jensen, W. \& Alhojärvi, J. 1959. On the digestibility of high yield chemical pulp and its evaluation. Acta Agriculturae Fenniae 94: 41-64.

Schofield, P., Pitt, R.E. \& Pell, A.N. 1994. Kinetics of fibre digestion from in vitro gas production. Journal of Animal Science 72 : 2980-2991.

Sjöström, E. 1993. Wood chemistry: fundamentals and applications. Academic Press. USA. 293 p.

Somogyi, M. 1945. A new reagent for the determination of sugars. Journal of Biological Chemistry 160: 61-68.

Song, T., Pranovich, A., Sumerskiy, I. \& Holmbom, B. 2008. Extraction of galactoglucomannan from spruce wood with pressurized hot water. Holzforschung 62: 659-666.

Stolter, C., Niemelä, P., Ball, J.P., Julkunen-Tiitto, R., Vanhatalo, A., Danell, K., Varvikko, T. \& Ganzhorn, J.U. 2009. Comparison of plant secondary metabolites and digestibility of three different boreal coniferous trees. Basic and Applied Ecology 10: 19-26.

Van Soest, P.J. 1994. Nutritional Ecology of the Ruminant. Cornell University Press. New York, USA. 476 p.

Van Soest, P.J., Robertson, J.B. \& Lewis, B.A. 1991. Methods for dietary fiber, neutral detergent fiber, and nonstarch polysaccharides in relation to animal nutrition. Journal of Dairy Science 74: 3583-3597.

Willför, S. \& Holmbom, B. 2004. Isolation and characterisation of water soluble polysaccharides from Norway spruce and Scots pine. Wood Science and Technology 38: 173-179.

Willför, S., Sundberg, A., Hemming, J. \& Holmbom, B. 2005. Polysaccharides in some industrially important softwood species. Wood Science and Technology 39: 245-258.

Willför, S., Pranovich, A., Tamminen, T., Puls, J., Laine, C., Suurnäkki, A., Saake, B., Uotila, K., Simolin, H.,Henning, J. \& Holmbom, B. 2009. Carbohydrate analysis of plant materials with uronic acid-containing polysaccharides-A comparison between different hydrolysis and subsequent chromatographic analytical techniques. Industrial Crop Production 29: 571-580.

Xu, C., Willför, S., Sundberg, K., Pettersson, C. \& Holmbom, B. 2007. Physicochemical characterization of spruce galactoglucomannan solutions: stability, surface activity and rheology. Cellulose Chemistry and Technology 51: 57-65.

Zelenak, I., Boda, K., Bucko, J., Jalc, D., Walko, T. \& Beseda, I. 1979. Wood molasses in the nutrition of ruminants. Annales De Recherches Veterinaires 10: 457-459.

Zinn, R.A. 1993. Comparative feeding value of wood sugar concentrate and cane molasses for feedlot cattle. Journal of Animal Science 71: 2297-2302. 